\title{
Erratum to: Hydrochemical characteristics of groundwater in the Kingston Basin, Kingston, Jamaica
}

\author{
A. Mandal ${ }^{1}$ - A. Haiduk ${ }^{2}$ C. Nawal ${ }^{1}$ E. Alleyne ${ }^{1}$
}

Published online: 24 March 2015

(c) Springer-Verlag Berlin Heidelberg 2015

\section{Erratum to: Environ Earth Sci (2011) 63:415-424 \\ DOI 10.1007/s12665-010-0835-5}

The authors would like to correct the errors in the original publication as detailed above. The correct version of the author lists and affiliations is given below:

A. Mandal ${ }^{1}$, A. Haiduk ${ }^{2}$, C. Nawal ${ }^{1}$ and E. Alleyne ${ }^{1}$

\section{Author affiliations}

${ }^{1}$ University of West Indies, Mona, Jamaica arpita_mandal2000@yahoo.com

${ }^{2}$ Water Resources Authority, Kingston, Jamaica

The online version of the original article can be found under doi:10.1007/s12665-010-0835-5.

$\triangle$ A. Mandal

arpita_mandal2000@yahoo.com

A. Haiduk

ahaiduk@wra.gov.jm

1 University of West Indies, Mona, Jamaica

2 Water Resources Authority, Kingston, Jamaica 